\title{
PROPERTIES OF NICKEL FILMS PREPARED BY R.F. SPUTTERING AND INTERDIFFUSION ANALYSIS OF $\mathrm{Ta}_{2} \mathbf{N}-\mathrm{Ni}$ FILMS
}

\author{
S. ABDIN, $\uparrow$ A. HUBER, G. MORILLOT and C. VAL \\ THOMSON-CSF - Domaine de Corbeville 91400 ORSAY \\ (Received March 13, 1980)
}

\begin{abstract}
$\mathrm{Ni}$ film deposition by r.f. sputtering and etching conditions have been investigated. The contact resistance and adhesion of this $\mathrm{Ni}$ layer deposited directly onto $\mathrm{Ta}_{2} \mathrm{~N}$ films have also been studied in air and at elevated temperatures. In this combination, the $\mathrm{Ta}_{2} \mathrm{~N} / \mathrm{Ni}$ interdiffusion analysis was carried out by the Secondary Ion Mass Spectroscopy (SIMS).
\end{abstract}

\section{INTRODUCTION}

A mechanically strong Nickel layer with a low contact resistance could be deposited directly on to Tantalum Nitride $\left(\mathrm{Ta}_{2} \mathrm{~N}\right)$ presputtered film.

The classical heat treatment of the generated $\mathrm{Ta}_{2} \mathrm{~N}$ film resistors can be done at $250^{\circ} \mathrm{C}$ for 16 hours without significant diffusion of Tantalum in the Nickel conductor layer. On the other hand the diffusion of Nickel in Tantalum decreases the contact resistance and improves the adherence between the two layers.

A nickel oxide layer less than $150 \AA$ is formed during the heat treatment. This layer was removed in the soldering process.

\section{FILM PREPARATION}

The nickel films were deposited by r.f. sputtering techniques ${ }^{1}$ using a Randex (model 3400) module.

Three types of substrates were used; corning glass, alumina (MRC) hybrid quality and optically polished alumina for SIMS analysis.

The glass substrates $(58 \times 70 \mathrm{~mm})$ were used in the study of the deposition rate and the resistivity of the $\mathrm{Ni}$ films as a function of the argon pressure and the input r.f. power. The choice of the glass substrates for these experiments was due to their good surface. The substrate-to-target distance was maintained at $5 \mathrm{~cm}$ and the back ground pressure

\footnotetext{
†University of Alexandra - Egypt.
}

was $6 \times 10^{-7}$ Torr. The target was a disc of 8 in diameter and sputtering was carried out at an r.f. input power of $1.5 \mathrm{~kW}$.

Figure 1a represents the resistivity $(\rho)$ and deposition rate (D) of the sputtered Ni films as a function of various argon pressures. The resistivity was determined by four point probe techniques. Deposition rate was determined by weight measurements before and after sputtering.

From Figure 1a, we see that the optimum condition to obtain low resistivity values necessitates an argon pressure in the range of 1.5 to $2.2 \times 10^{-2}$ Torr. At $3 \times 10^{-2}$ Torr, the deposition rate decreases with increasing pressure. This is due to the excessive collisions of the ejected atoms which prevented them from reaching the anode.
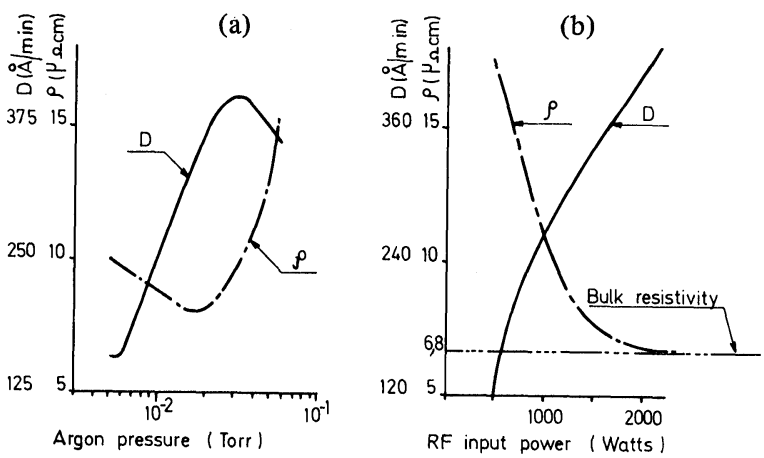

FIGURE 1 (a) Resistivity and deposition rate vs. argon pressure. (b) The dependance of resistivity and deposition rate on the r.f. input power. 
In Figure 1.b, the deposition rate and the resistivity are plotted against the r.f. input power for argon pressure of $1.7 \times 10^{-2}$ Torr and sputtering time of 20 minutes. At input power of $2.5 \mathrm{~kW}$, the resistivity reaches its theoretical bulk value of $6.84 \mu \Omega \mathrm{cm}$.

\subsection{Contact Resistance and Adhesion Measurements}

In the present study, the $\mathrm{Ni}$ layers were deposited on alumina ceramic substrates $(50 \times 50 \mathrm{~mm})$, which were precoated with reactively sputtered $\mathrm{Ta}_{2} \mathrm{~N}$ $(500 \AA, \rho=250 \mu \Omega \mathrm{cm} \text {. })^{2}$ The effect of accelerated ageing conditions on both contact resistance and adhesion to $\mathrm{Ta}_{2} \mathrm{~N}$ have been investigated.

A special test mask was designed with intermittent resistor pattern and conductor pads (see Figure 2a). To obtain the required thin film pattern, a selective etching method was used. It was found that the best etching solution for $\mathrm{Ni}$ films is cerium nitride at $35^{\circ} \mathrm{C}$, with etching rate of $350 \AA / \mathrm{min}$. The other etching solutions such as iron chloride left a veil of nickel oxide.

The pattern used for the contact resistance measurements had four intermittent $\mathrm{Ta}_{2} \mathrm{~N}$ resistors each of one third square in series with five squares $\mathrm{Ni}$ coated resistors. We have used the following equation to deduce the values of the contact resistance $(R c)$.

$$
R c=\frac{R t+3 R s-\sum_{4}^{1} R i}{6}
$$

where $R t, R s$ and $R i$ are the total resistance of the intermittent pattern, the sheet resistance of conductor coated $\mathrm{Ta}_{2} \mathrm{~N}$ and the $\mathrm{Ta}_{2} \mathrm{~N}$ intermittent resistances respectively.

The initial contact resistance between the $\mathrm{Ta}_{2} \mathrm{~N}$ and $\mathrm{Ni}$ layers measured from as prepared intermittent resistors ranged between $60 \mathrm{~m} \Omega /$ contact and $100 \mathrm{~m} \Omega$ contact. After ageing in accelerated conditions in air at $250^{\circ} \mathrm{C}$ for 16 hours and then at $150^{\circ} \mathrm{C}$ for 2000 hours, the contact resistances were always stable and showed no change in their initial values.

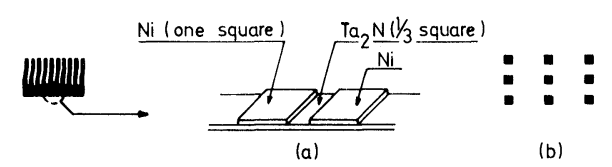

FIGURE 2 Parts of the test pattern used in (a) contact resistance measurements (b) pads for adhesion test.

\subsection{Adhesion Test}

For the adhesion test, we used the wire peel test "Du Pont Test" 3 and each alumina substrate had nine test pads of uniform size, $2.0 \times 2.0 \mathrm{~mm}$ (see Figure $2 \mathrm{~b}$ ). In this method, a $0.6 \mathrm{~mm}$ tin-plated copper wire is bent at one end to enable it to be soldered onto the conductor pad. The $\mathrm{Ta}_{2} \mathrm{~N} / \mathrm{Ni}$ films are heat treated firstly at $250^{\circ} \mathrm{C}$ for 16 hours and then the soldering process was done by dipping in a bath of molten solder held at a constant temperature at $220^{\circ} \mathrm{C}$ for 5 seconds. The measurements were made on a tensile testing machine Istron.

Figure 3 shows the breaking strength as a function of the time of heat treatment for different temperatures. In each case the breaking strength was averaged over three substrates ( 27 pads).

In this test it was noted that:

1) The Ni layer was scratched and left the $\mathrm{Ta}_{2} \mathrm{~N}$ layer which has a good adhesion to the alumina substrate.

2) Some measurements at $20^{\circ} \mathrm{C}$ were carried out on the adhesion of Ni layers directly sputtered on alumina and the breaking strength value was found to be approximately that of $\mathrm{Ni} / \mathrm{Ta}_{2} \mathrm{~N}$ layers $(7.5 \mathrm{~kg} / \mathrm{pad})$.

3) After ageing in either of the accelerated conditions, the Ni layer succeeded the scotch tape test.

From the above remarks, we see the possibility of device application of $\mathrm{Ta}_{2} \mathrm{~N} / \mathrm{Ni}$ system where $\mathrm{Ta}_{2} \mathrm{~N}$ film was in direct contact with the Ni film.

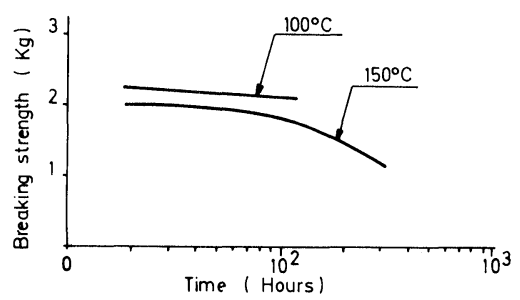

FIGURE 3 Breaking strength vs. time of heat treatment at $100^{\circ} \mathrm{C}$ and $150^{\circ} \mathrm{C}$ for pad area of $4 \mathrm{~mm}^{2}$.

\section{INTERDIFFUSION ANALYSIS}

The method used for the study of the diffusion between $\mathrm{Ta}_{2} \mathrm{~N}$ and $\mathrm{Ni}$ layers is the secondary ion mass spectrometry (SIMS). The Ni and Ta profiles in our samples have been determined by a CAMECA 
IMS 300 ion analyzer. ${ }^{4}$ The measurement of the amplitude of $\mathrm{Ni}$ and $\mathrm{Ta}$ ion signals was carried out from the heat treated nickel film on $\mathrm{Ta}_{2} \mathrm{~N}$ as a function of the depth.

The instrument is designed in such a way that only the ions from the centre of the eroded crater (which has a surface area of $7 \times 10^{-2} \mathrm{~mm}^{2}$ ) are analyzed, thus eliminating the effect of the redistribution of ions coming from the outer area. The depth of the crater was measured by an optical interference technique. The crater is produced by scanning the ion beam, its bottom is flat and depth profiling can be obtained with a resolution $\sim 150 \AA$.

Some remarks on interpretation of the SIMS result.

i) The ion amplitudes are presented in relative intensity, while we do not have standard samples for the quantitative analysis.

ii) The ion yields of one element could be varied by many orders of magnitude from one matrix to another (matrix effect), so ion signal linearity does not exist for the same element in the two layers of different nature.

Figure 4 summarizes the $\mathrm{Ni}$ and Ta profiles in relative intensity (internal standard ${ }^{2} \mathrm{Al}^{+}$was used from $\mathrm{Al}_{2} \mathrm{O}_{3}$ ) as a result of annealing at $250^{\circ} \mathrm{C}$ for 16 hours, $450^{\circ} \mathrm{C}$ and $600^{\circ} \mathrm{C}$ for one hour. In this

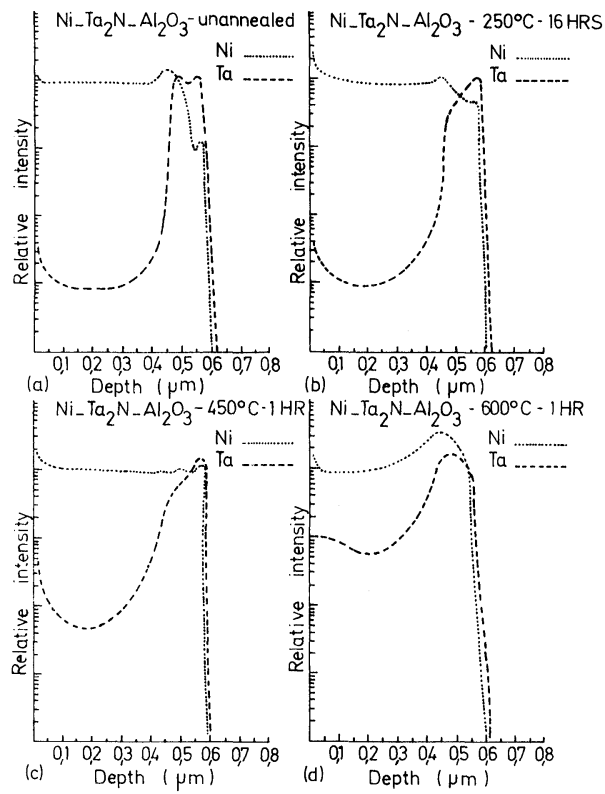

FIGURE $4 \quad \mathrm{Ni}$ and Ta profiles as a function of depth. (a) unannealed; (b) annealed at $250^{\circ} \mathrm{C}, 16 \mathrm{~h}$; (c) $450^{\circ} \mathrm{C}, 1 \mathrm{~h}$; (d) $600^{\circ} \mathrm{C}, 1 \mathrm{~h}$. figure $\mathrm{Ni}$ and $\mathrm{Ta}$ profiles of an unannealed sample are also presented.

We can make the following remarks on interdiffusion analysis:

1) In Figure 4a, the existence of a certain quantity of nickel in the unannealed $\mathrm{Ta}_{2} \mathrm{~N}$ layer is related to the preparation conditions. During r.f. sputtering of $\mathrm{Ni}$, the film temperature was sufficiently raised ${ }^{5}$ to cause some $\mathrm{Ni}$ diffusion in the $\mathrm{Ta}_{2} \mathrm{~N}$ film.

2) With increasing annealing temperature there is more $\mathrm{Ni}$ diffusion in the $\mathrm{Ta}_{2} \mathrm{~N}$ film.

3) We observe neither Ni nor Ta diffusion in the alumina substrates up to $450^{\circ} \mathrm{C}$, a slight diffusion can be observed at $600^{\circ} \mathrm{C}$.

4) Ta diffusion in Ni layer became evident up to $450^{\circ} \mathrm{C}$ and at $600^{\circ} \mathrm{C}$ we observed an important diffusion of $\mathrm{Ta}$ in $\mathrm{Ni}$.

5) The higher ion intensity was observed at the surface and different interfaces could be attributed to the enhancement of the ion signal due to the presence of chemisorbed oxygen. ${ }^{6}$

6) The ion profile of $\mathrm{N}_{2}$ as a function of depth was also studied. We found a homogeneous distribution of $\mathrm{N}_{2}$ in the $\mathrm{Ta}_{2} \mathrm{~N}$ film and a slight diffusion of $\mathrm{N}_{2}$ in the $\mathrm{Ni}$ film was also noted.

\section{CONCLUSION}

It has been shown in this study that metallizing $\mathrm{Ta}_{2} \mathrm{~N}$ films directly with $\mathrm{Ni}$ conductor films using r.f. sputtering techniques can give satisfying results for contact resistance and adhesion. Moreover, soft solder can be used between the Ni layer and outer connection which simplifies the soldering process.

The contact resistance changes and the breaking strength were examined as a function of heat treatment temperature and time. In these conditions, the contact resistance was stable and the conductor pads succeeded the scotch tape test. Interdiffusion analysis showed a slight diffusion of $\mathrm{Ta}$ in $\mathrm{Ni}$ film for temperatures of classical heat treatment, this diffusion has no effect on the solderability of Ni.

\section{ACKNOWLEDGEMENTS}

The authors wish to thank M. JP. Truffer for his help in film preparation and M. P. Merenda for helpful discussion. 


\section{REFERENCES}

1. P. D. Davidse, and L. I. Maissel, "Dielectric thin films through r.f. sputtering," J. Appl. Phys. 37 (1966) 574-79.

2. S. Abdin and C. Val, "Production of tantalum nitride film resistors by using continuous sputtering machine," Proc. 4th Int. Thin Solid Films Conf., Loughborough Univ. U.K. Sept. 15-19 (1978).

3. E. I., Du Pont, Technical Report, Thick film conductor compositions, Wilmington 19898 (Nemours-France).
4. A. M., Huber, "La caractérisation des matériaux semiconducteurs." (French), Seminaire Franco-Polonais Varsovie June 2-4 (1975) Publ. by Institut de technologie Warszawa (1976) 223.

5. S. S., Lau, R. H. Mills and D. G. Muth, "Temperature rise during film deposition by r.f. and d.c. sputtering," J. Vac. Sci. Technol., 9 (July-August 1972) 1196-1202.

6. G. Slodzian and J. F. Hennequin, Compte rendu Acad. Sc. Paris 263 B (French) (1968) 1246. 

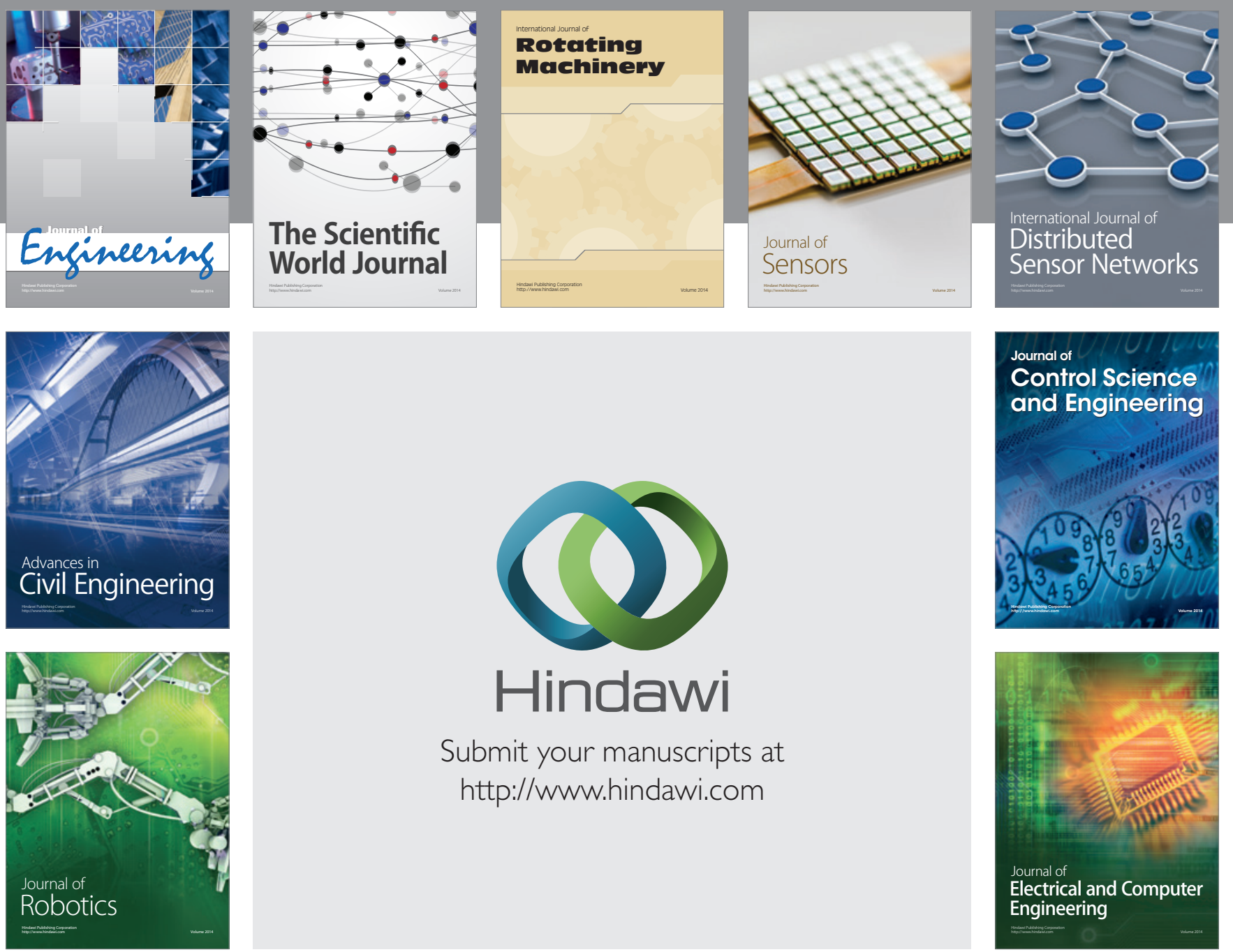

Submit your manuscripts at

http://www.hindawi.com
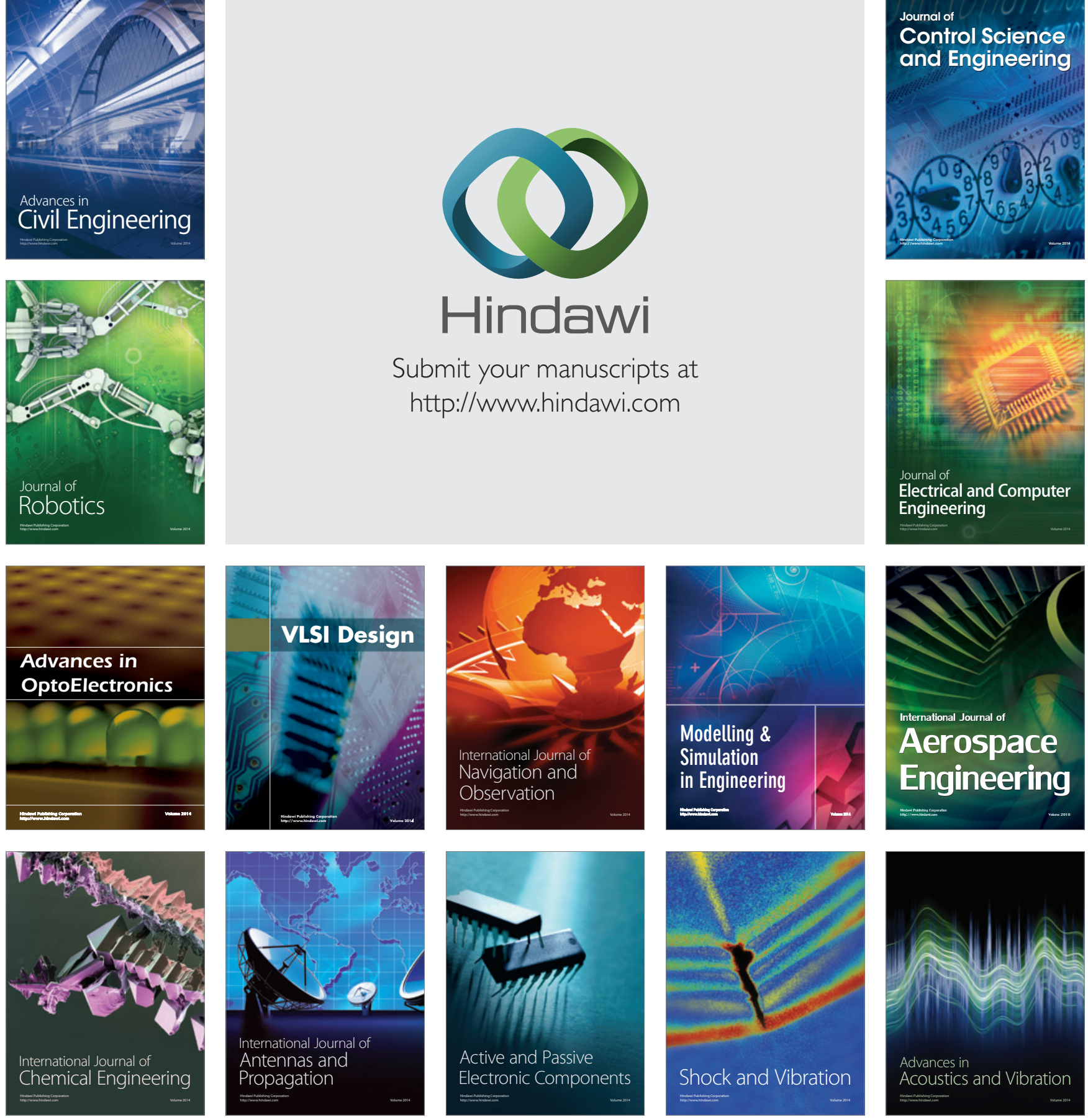